\title{
Pollination in a degraded tropical landscape: a Hong Kong case study
}

\author{
RICHARD T. CORLETT
}

Department of Ecology and Biodiversity, University of Hong Kong, Pokfulam Road, Hong Kong, China

(Accepted 3rd August 2000)

KEY WORDS: China, pollination, pollinators, flower visitors, Apis cerana, Gnetum

Although the pollination biology of many individual plant species has been investigated in the Oriental region, there have been very few community-level studies. The two most comprehensive of these were in the primary mixed dipterocarp forest of Lambir Hills National Park, Sarawak $\left(4^{\circ} 20^{\prime} \mathrm{N}\right.$ : Momose et al. 1998, Sakai et al. 1999) and in the warm temperate evergreen broad-leaved forest and cool temperate mixed forest on Yakushima Island $\left(30^{\circ} \mathrm{N}\right.$ : Yumoto 1987, 1988). Hong Kong $\left(22^{\circ} 17^{\prime} \mathrm{N}\right)$ lies midway between these sites, at the northern margin of the tropics, where winter temperatures fall below $10^{\circ} \mathrm{C}$ at sea-level for a few days every year and there are occasional frosts above 400 m (Dudgeon \& Corlett 1994). Latitudinal effects, however, are compounded in comparisons with other well-studied East Asian sites, by centuries of massive human impact, leaving a degraded landscape of steep, eroded hillsides, covered in fire-maintained grassland, secondary shrublands and, locally, secondary forests (Zhuang \& Corlett 1997). This history has left a relatively impoverished fauna but a surprisingly diverse flora, including 400 native tree species (Corlett \& Turner 1997). In these circumstances, failures of pollination and dispersal mutualisms might be expected to accelerate the loss of plant species from the landscape (Bond 1994, Kearns \& Inouye 1997). Previous studies have shown that most woody vegetation in Hong Kong is dominated by species whose seeds can be dispersed by the commonest avian frugivores, the light-vented and red-whiskered bulbuls (Pycnonotus sinensis (Gmelin) and P. jocosus (Linn.)) and the Japanese white-eye (Zosterops japonicus Swinhoe) (Corlett 1996, 1998), but there is no equivalent information available on pollination biology. 
I report here a preliminary survey of the major flower visitors and probable pollinators of 83 common woody species of shrubland and secondary forest. These communities have a March-May flowering maximum and a December minimum (Corlett 1993). Systematic observations were made on approximately twice-monthly, morning walks along two 5-6-km routes on Hong Kong Island from July 1997 to May 2000. These were supplemented by additional observations targeted at particular species and at other times of the day and night. I have also made use of 12 y of casual observations in the same area and elsewhere in Hong Kong. Only flower visitors that were observed in at least two years on a particular plant species are reported here. From January to May 1998, and occasionally thereafter, an electronic thermometer was used to measure air temperatures adjacent to active flower visitors to determine the minimum temperature for activity of the major species. Major flower visitors, except flies and wasps, were identified to the species or genus level, but numerous minor visitors, for which species-specific associations were not apparent, have been combined into higher taxonomic groups (Appendix 1). Further work would probably find plant-insect associations involving these species which were missed in this preliminary study. Plant names follow Corlett et al. (2000), which also explains nomenclatural changes since earlier publications on the ecology of Hong Kong, as well as giving information on growth forms, habitats and conservation status.

Apis cerana F., which is the only Apis species in Hong Kong, was by far the most important flower visitor. It visited 71 of the 83 species (86\%) and was the numerically dominant visitor on 46 (55\%) of these. In most cases, the behaviour of Apis during flower visits suggested it was probably an effective pollinator. However, this bee also collected the loose, dry pollen from the apparently wind-pollinated Quercus myrsinifolia and visited only male plants of the dioecious, and probably also wind-pollinated, Aporosa dioica and Mallotus paniculatus (both Euphorbiaceae). Visits to Myrsine seguinii were also overwhelmingly to male plants, as were most visits to Litsea glutinosa. Apis cerana is found in all plant communities in Hong Kong, from mangrove forest to montane forest and grassland at $900 \mathrm{~m}$. This bee is active throughout the year but it was not seen at air temperatures below $11-12^{\circ} \mathrm{C}$ and it was active at 12 $15^{\circ} \mathrm{C}$ only on dry, still days. At higher temperatures, the bees continued to visit flowers in light rain but disappeared before heavy rain.

Most of the plant species for which Apis visits were rare or absent were visited by carpenter bees, lepidoptera, wasps or calliphorid flies. Several species of carpenter bee, Xylocopa spp., were apparently the only pollinators of Melastoma sanguineum, and also predominated on Fagerlindia canthiodes and Rhodomyrtus tomentosa. Melastoma sanguineum has apically porose anthers from which the pollen must be 'buzzed', which Apis cerana is apparently unable to do. Various smaller bees that visited Melastoma and Rhodomyrtus did not usually contact the stigmas. Carpenter bees were active only in air temperatures above $23-25^{\circ} \mathrm{C}$ 
and were common only from late April to early September. Elsewhere in Hong Kong, but not in the study area, a large bumblebee, Bombus eximius Smith, is a common visitor to medium and large flowers in the cooler months (JanuaryMay), and is active in worse weather and at lower temperatures $\left(>8^{\circ} \mathrm{C}\right)$ than any other local flower visitor ( $\mathrm{Ng} \&$ Corlett 2000). Many smaller bee species visited flowers in the warmer months (June-September) but none of these was the major visitor to any of the plant species under observation. A great variety of wasps were the major visitors to two species of Psychotria and large vespids were the commonest visitors and likely major pollinators of the winterflowering Gordonia axillaris. No wasps visited flowers below $12{ }^{\circ} \mathrm{C}$.

Seven plant species were visited, and apparently pollinated, largely or entirely by Lepidoptera. Only papilionid butterflies (Papilio spp. and Graphium spp.) and occasional hawkmoths visited Mussaenda pubescens, Pavetta hongkongensis and Pittosporum glabratum, which have long corolla tubes. Acronychia pedunculata was visited largely by nymphalids, while Ehretia longiflora and Reevesia thyrsoidea were visited by a wider range of butterflies, as well as diurnal hawkmoths and nocturnal moths. No lepidoptera were seen visiting flowers at air temperatures below $14{ }^{\circ} \mathrm{C}$ and most visits below $20^{\circ} \mathrm{C}$ were by pierids.

The only species visited predominantly by nocturnal moths (mostly noctuids) was the dioecious gymnosperm climber, Gnetum luofuense. In this species, moth visits to both male and female plants coincided with nectar secretion and the production of a strong, sweetish odour, which started just before sunset and declined gradually after midnight. Less common visitors to Gnetum luofuense included lacewings (Neuroptera), katydids (Orthoptera), cockroaches (Blattodea) and beetles. Apis cerana occasionally collected pollen from male strobili during the day. Although it has been suggested that this pollination mechanism, involving the production of exposed nectar, is dependent on the high humidity of the rain forest understorey (Kato et al. 1995), both flower visits and seed set were equally frequent on isolated plants in open shrubland in Hong Kong.

Calliphorid flies predominated on two Lithocarpus spp. and the winterflowering Embelia ribes. Syrphid flies were also common flower visitors in winter and were the most frequent visitors to Sageretia thea. Flies from several other families were occasional flower visitors, particularly in winter. No flies visited flowers below $12^{\circ} \mathrm{C}$. Beetles from several families (Cerambycidae, Chrysomelidae, Melyridae and Scarabaeidae) were irregular visitors - sometimes in large numbers - to several species, but were the dominant visitor on none.

Birds (the Japanese white-eye, Zosterops japonica and fork-tailed sunbird, Aethopyga christinae Swinhoe) were frequent visitors to the large, crimson-pink, flower-like heads of Rhodoleia championii, and the large, pink bells of Enkianthus quinqueflorus, and occasional visitors to the large, white, open flowers of Gordonia axillaris. In the first two species, these birds are probably the major pollinators.

In addition to the 83 woody plant species in Appendix 1, for which adequate 
observations of flower visitors were obtained, no visitors were seen to flowers of Garcinia oblongifolia and Sterculia lanceolata, despite several hours of cumulative observation time, including visits at night. Both these species produce numerous small flowers but only a few, large fruits each year, so it is possible that rare pollinators were simply overlooked.

The only other study of flower visitors to woody plants in Hong Kong compared visitation rates of potential pollinators to the six native species of Rhododendron, which flower in March and April (Ng \& Corlett 2000). Although the flower visitors included species from four orders of insects and the fork-tailed sunbird, the bumblebee, Bombus eximius, which flies throughout the flowering season, and carpenter bees, Xylocopa spp., which do not become active until April, were considered the most effective pollinators for all six species on a per-visit basis, because their large sizes ensured contact with both the stigma and anthers. However, Apis cerana, despite its small size and infrequent contacts with the stigma, was probably the most important pollinator early in the flowering season at sites where Bombus was absent, and later on for two smallerflowered Rhododendron species which rarely attracted Xylocopa bees.

Pollination systems are very different in the lowland dipterocarp forest of Sarawak (Momose et al. 1998, Sakai et al. 1999). Of the 305 plant species monitored over $53 \mathrm{mo}, 25 \%$ were pollinated by small, non-Apis social bees (particularly Trigona species), 23\% by beetles, 14\% by 'diverse insects' (beetles, flies, bees, etc.) and only $11 \%$ by Apis bees. Birds, bats, lepidoptera and solitary bees played a relatively minor role. Apis cerana is not mentioned but the ecologically similar, although slightly larger, $A$. koschevnikovi was the main pollinator of several species. However, the most important Apis pollinator was the much larger $A$. dorsata, which appears as a migrant during supra-annual mass flowering episodes in Sarawak and is absent from Hong Kong. Most beetle-pollinated species were in the families Dipterocarpaceae and Myristicaceae, which are entirely absent from Hong Kong, or the Annonaceae, which are present but were not included in my study sample.

Both the vascular plant flora and flower-visiting fauna on Yakushima Island are very similar at the family level to those of Hong Kong (Yumoto 1987, 1988). However, although Apis cerana is present on the island, it was not an important pollinator at the forest sites studied, while non-Apis bees (including Bombus), flies and beetles were more important than in Hong Kong. Flies were the main visitors to Myrsine seguinii and Schefflera octophylla, which also occur in Hong Kong, where they are visited by Apis alone and Apis plus a wide range of other insects, respectively.

The dominance of Apis cerana as a visitor to flowers of woody plants in Hong Kong seems to be largely a reflection of the rarity of other bees during the March-May flowering maximum. The extent to which Hong Kong's several hundred-year history of massive human impact has contributed to this is impossible to determine, since there is no large area of undisturbed vegetation 
in the Hong Kong region to serve as a baseline for comparison. However, the relatively minor role of resident Apis bees in intact forests in both Sarawak and Yakushima suggests that the same may also have been true in Hong Kong, before deforestation. Bee diversity is much higher in Hong Kong from mid June to early September, but relatively few plant species are in flower during this period, perhaps because this is the wettest part of the year. If Apis cerana is an effective pollinator of most of the species it visits - and further work will be needed to confirm this - the abundance and ubiquity of this bee may have contributed to the surprising resilience of Hong Kong's woody flora in the face of extreme landscape degradation.

\section{ACKNOWLEDGEMENTS}

I would like to thank David Dudgeon for help with identification of pollinators and Ng Sai-Chit for sharing his field observations.

\section{LITERATURE GITED}

BOND, W. J. 1994. Do mutualisms matter? Assessing the impact of pollinator and disperser disruption on plant extinction. Philosophical Transactions of the Royal Society of London B 344:83-90.

CORLETT, R. T. 1993. Reproductive phenology of Hong Kong shrubland. Journal of Tropical Ecology 9:501-510.

CORLETT, R. T. 1996. Characteristics of vertebrate-dispersed fruits in Hong Kong. Journal of Tropical Ecology 12:819-833.

CORLETT, R. T. 1998. Frugivory and seed dispersal by birds in Hong Kong shrubland. Forktail 13:23-27.

CORLETT, R. T. \& TURNER, I. M. 1997. Long-term survival in tropical forest remnants in Singapore and Hong Kong. Pp. 333-345 in Laurance, W. F. \& Bierregaard, R. O. (eds). Tropical forest remnants: ecology, management and conservation of fragmented communities. University of Chicago Press, Chicago.

CORletT, R. T., XING, F., NG, S. G., CHAU, K. G. \& WONG, M. Y. 2000. Hong Kong vascular plants: distribution and status. Memoirs of the Hong Kong Natural History Society 23:1-157.

DUDGEON, D. \& CORLETT, R. T. 1994. Hills and streams: an ecology of Hong Kong. Hong Kong University Press, Hong Kong.

KATO, M., INOUE, T. \& NAGAMiTSU, T. 1995. Pollination biology of Gnetum (Gnetaceae) in a lowland mixed dipterocarp forest in Sarawak. American Journal of Botany 82:862-868.

KEARNS, C. A. \& INOUYE, D. W. 1997. Pollinators, flowering plants, and conservation biology. Much remains to be learned about pollinators and plants. Bioscience 47:297-307.

MOMOSE, K., YUMOTO, T., NAGAMiTSU, T., KATO, M., NAGAMASU, H., SAKAI, S., HARRISON, R. D., ITIOKA, T., HAMID, A. A. \& INOUE, T. 1998. Pollination biology in a lowland dipterocarp forest in Sarawak, Malaysia. I. Characteristics of the plant-pollinator community in a lowland dipterocarp forest. American Journal of Botany 85:1477-1501.

NG, S. C. \& CORLETT, R. T. 2000. Comparative reproductive biology of the six species of Rhododendron (Ericaceae) in Hong Kong, South China. Canadian Journal of Botany 78:221-229.

SAKAI, S., MOMOSE, K., YUMOTO, T., NAGAMITSU, T., NAGAMASU, H., HAMID, ABANG. A. \& NAKASHIZUKU, T. 1999. Plant reproductive phenology over four years including an episode of general flowering in a lowland dipterocarp forest, Sarawak, Malaysia. American Journal of Botany 86:1414-1436.

YUMOTO, T. 1987. Pollination systems in a warm temperate evergreen broad-leaved forest on Yaku Island. Ecological Research 2:133-145.

YUMOTO, T. 1988. Pollination systems in the cool temperate mixed coniferous and broad-leaved forest zone of Yakushima Island. Ecological Research 3:117-129.

ZHUANG, X. \& CORLETT, R. T. 1997. Forest and forest succession in Hong Kong, China. Journal of Tropical Ecology 14:857-866. 


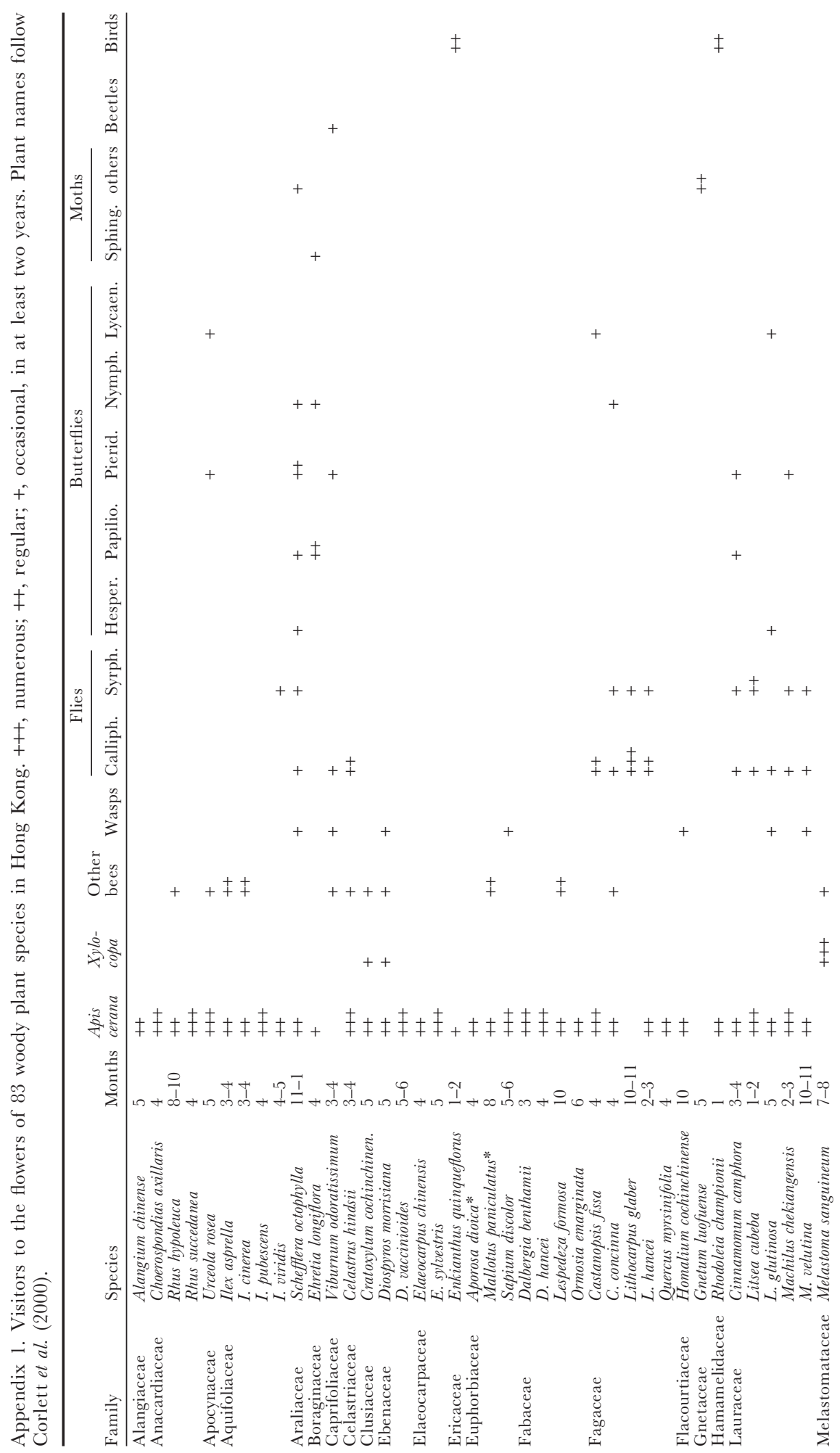




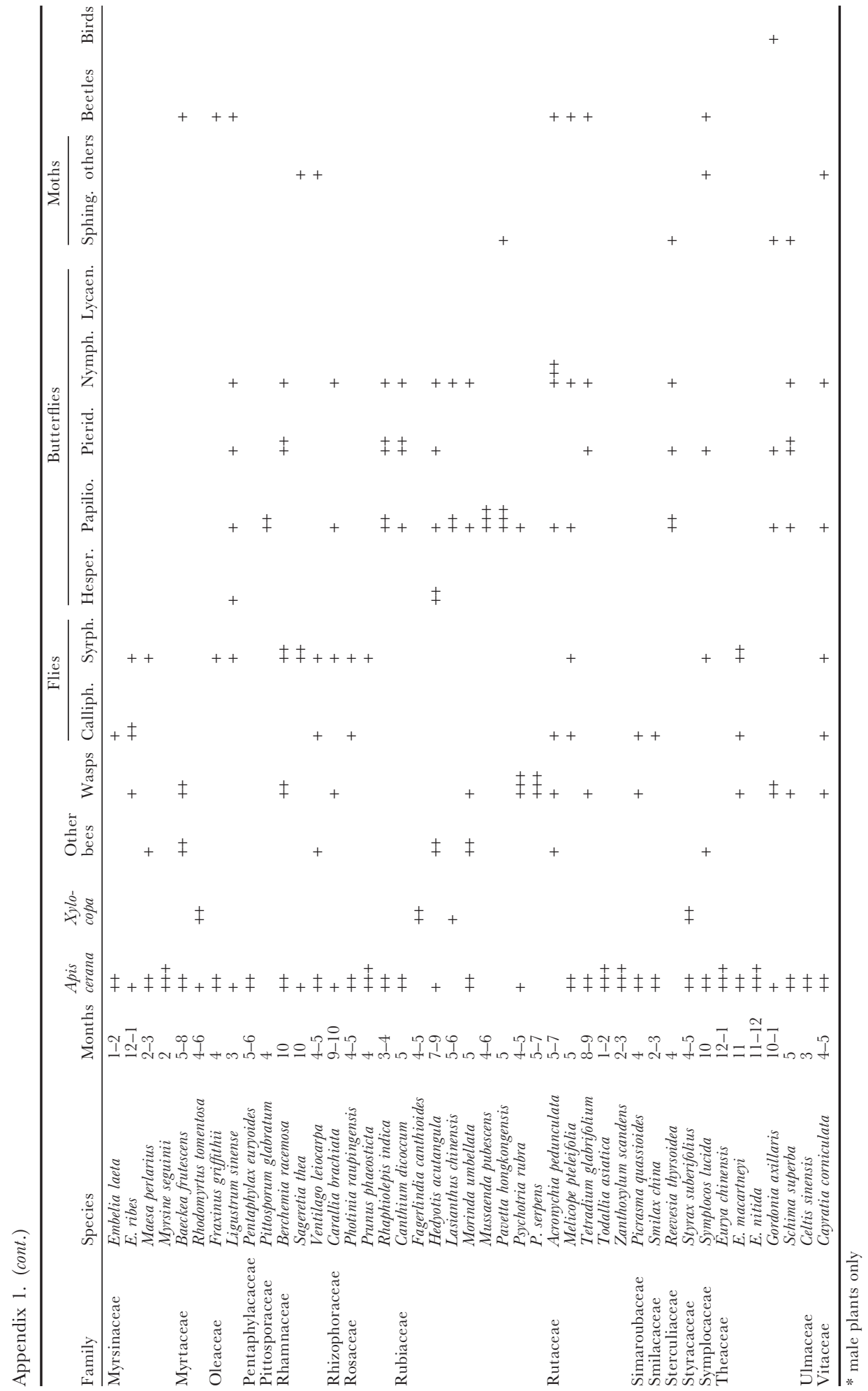

